Artigo original

Hegemonia - Revista Eletrônica de Relações Internacionais do Centro Universitário Unieuro

ISSN: $1809-1261$

UNIEURO, Brasília, número 10, 2012, pp. 4-19.

Recebido em: 1/4/2012

Revisado em: 18/5/2012

Aprovado em: 29/6/2012

\title{
México e Brasil: papéis distintos no Nafta e no Mercosul
}

CARMO, Erinaldo Ferreira do ${ }^{1}$

RESUMO: Desde o fim da Guerra Fria, os países da América têm se organizado em blocos para ampliação de mercados econômicos. Nas duas extremidades do Continente formaram-se dois blocos em períodos próximos, mas com perfis diferenciados. Também diferentes são os papéis assumidos pelo México e pelo Brasil em seus respectivos blocos. De um lado, o Nafta - North American Free Trade Agreement, onde o México tem papel secundário, e de outro o Mercosul - Mercado Comum do Sul, autônomo em relação aos Estados Unidos e tendo o Brasil como agente central. É sobre estes dois países, em seus respectivos mercados, o que este artigo aborda.

Palavras-chave: América Latina, Mercosul, Nafta, Relações Internacionais.

ABSTRACT: Since the end of the Cold War, countries have been organized into blocks for expansion of economic markets. In America, two sets at the two ends of the continent, formed in the coming periods, but with different profiles. Also different are the roles

Doutor em Ciência Política, Professor do Colégio de Aplicação do Centro de Educação da Universidade Federal de Pernambuco. 
Artigo original

Hegemonia - Revista Eletrônica de Relações Internacionais do Centro Universitário Unieuro

ISSN: $1809-1261$

UNIEURO, Brasília, número 10, 2012, pp. 4-19.

undertaken by Mexico and Brazil in their respective markets. On the one hand, Nafta - North American Free Trade Agreement, where Mexico play a secondary role, and the other Mercosur - Common Southern Market, independent from the United States and Brazil as having the central agent. It's about these two countries in their respective markets, this article discusses.

Keywords: Latin America, Mercosur, NAFTA, International Relations.

\section{A retomada da democracia no México e no Brasil}

Até a primeira década do século passado o México viveu sob a ditadura de José de la Cruz Porfirio Díaz Mory, militar que governou por 31 anos. Após este longo período autoritário, o país passou por outra experiência não-democrática através do PRI - Partido Revolucionário Institucional, que permaneceu por sete décadas no poder. O PRI foi instituído em 1929 por Plutarco Elías Calles, que havia presidido o México de 1924 a 1928. Inicialmente recebeu o nome de Partido Nacional Revolucionário, posteriormente passou a ser denominado de Partido da Revolução Mexicana e só a partir de 1946 adotou a atual nomenclatura.

A longa permanência do PRI no poder deveu-se, em grande parte, à concentração de forças do partido, agrupando as principais lideranças políticas nacionais; às ações populistas que 
Artigo original

Hegemonia - Revista Eletrônica de Relações Internacionais do Centro Universitário Unieuro

ISSN: $1809-1261$

UNIEURO, Brasília, número 10, 2012, pp. 4-19.

arregimentaram os trabalhadores em sua estrutura organizacional, incluindo a Confederação dos Trabalhadores Mexicanos e a Confederação Nacional Camponesa; e às fraudes eleitorais, como a ocorrida em 1988, na eleição de Carlos Salinas de Gotari, que através de um processo eleitoral tumultuado e violento surpreendeu o povo mexicano na totalização das urnas ao receber mais votos que o favorito Chuauhtémoc Cárdenas, candidato de esquerda pelo Partido Revolucionário Democrático.

O governo de Salinas de Gorati foi marcado pelo incentivo às privatizações e pela ampliação das importações, elevando o endividamento do Estado e a crise financeira nacional, fortalecendo sua dependência diante dos Estados Unidos. Em 1993 Salinas acordou a entrada do México no Nafta, sem obstáculos entre os setores políticos e econômicos do país, apontando-o como melhor alternativa para um país enfraquecido economicamente.

A eleição de Vicente Fox, em 2000, pelo PAN - Partido da Ação Nacional, de centro-esquerda, representou um marco político para a história recente mexicana. Depois de ter passado todo o século $X X$ sob regimes autoritários e semidemocráticos, no último ano a democracia foi restabelecida. O PAN também elegeu, em 2006, o sucessor de Fox, o atual presidente Felipe Calderón.

No Brasil, diferente do México, o período sem os preceitos democráticos teve uma duração menor. No século passado, o país foi semidemocrático de 1930 a 1934, durante o mandato de Getúlio 
Artigo original

Hegemonia - Revista Eletrônica de Relações Internacionais do Centro Universitário Unieuro

ISSN: $1809-1261$

UNIEURO, Brasília, número 10, 2012, pp. 4-19.

Vargas como chefe do governo provisório, estabelecido com a Revolução de 30, sem a realização de eleições; autoritário de 1937 a 1945, ainda com Vargas, após o golpe de estado; e de 1964 a 1984, durante a ditadura militar. Em 1985, com a morte de Tancredo Neves, presidente eleito indiretamente através de um colégio eleitoral, tomou posse o vice-presidente, José Sarney, que promoveu a transição pacificamente, convocou a Constituinte e governou até 1990, quando então Fernando Collor de Mello assumiu o governo conquistado com a eleição de 1989, a primeira posterior às duas décadas de ditadura militar. A experiência autoritária brasileira foi menos extensa que a mexicana. Entretanto, o México teve um longo período de semidemocracia, enquanto o Brasil passou diretamente do modelo autoritário para o democrático em uma transição pacífica.

A classificação aqui adotada para autoritarismo, semidemocracia e democracia segue 0 modelo elaborado por Mainwaring et alii (2001). Nele, o México se enquadra como um país de regime autoritário até 1987, e a partir daí entra em um regime semidemocrático, que se estende até 1999. Apesar de passar um período bem maior sem democracia, o povo mexicano não conheceu, na contemporaneidade, o autoritarismo como o ocorrido no Brasil com a ditadura militar. Mesmo quando quase toda a América Latina se consumia com governos militares, na segunda metade do século $\mathrm{XX}$, no México o poder permaneceu nas mãos de governos civis, enquanto em outros países, principalmente da América do Sul, 
Artigo original

Hegemonia - Revista Eletrônica de Relações Internacionais do Centro Universitário Unieuro

ISSN: $1809-1261$

UNIEURO, Brasília, número 10, 2012, pp. 4-19.

incluindo o Brasil, os regimes autoritários mantinham-se sob os efeitos perniciosos da ditadura fardada.

Na classificação de um país como de regime democrático, segundo Mainwaring et alii (2001), o primeiro critério observado é se os cargos de governo e do parlamento são submetidos à escolha do povo, através de processo competitivo, livre e limpo. O segundo critério é a existência do sufrágio universal, o que garante o direito de participação de larga parcela da população nacional, excluindo apenas os casos admissíveis (por não atingir a idade legalmente estipulada ou por condenações judiciais que impeçam o ato de votar). Estes dois primeiros critérios são considerados por Dahl (1971) como as dimensões clássicas da democracia representativa moderna.

O terceiro critério observado para classificação de um Estado como democrático é se os direitos políticos e as liberdades civis são respeitados, aqui incluindo a liberdade de imprensa, de expressão, de organização e de não ser preso arbitrariamente, sendo estes direitos protegidos por garantias constitucionais. O quarto critério é a certeza de que as autoridades eleitas possuem condições reais para o exercício de governo, sem a ingerência de forças militares.

Portanto, Brasil e México são considerados Estados democráticos a partir de 1985 e 2000, respectivamente, por realizarem eleições abertas e limpas para o Legislativo e o Executivo; permiterem a universalização do direito de voto; garantirem as liberdades civis e os direitos políticos aos seus cidadãos; e serem, de 
Artigo original

Hegemonia - Revista Eletrônica de Relações Internacionais do Centro Universitário Unieuro

ISSN: $1809-1261$

UNIEURO, Brasília, número 10, 2012, pp. 4-19.

fato, governados por políticos eleitos para isto, sem submissão aos militares. Esta descrição minimalista da democracia, utilizada por Mainwaring et alii (2001), é aplicada de maneira simplificada a este trabalho, mas sem negar a existência de outros critérios inerentes ao Estado democrático, entretanto considerando estes como essenciais e de fácil identificação nos países observados.

Os quatro critérios adotados para indicar se um Estado é gerido através de um regime democrático somam um conjunto de valores que não surtem efeitos se observados isoladamente, ou se ao menos um deles não for adotado. E a falta de um desses critérios não pode ser compensada, nem mesmo com a ampliação de outro. Regimes que promovem eleições competitivas, mas não protegem as liberdades civis, bem como regimes que garantem as liberdades civis, e não permitem que o governo exerça de fato o controle do Executivo, não constituem Estados democráticos.

De acordo com estas considerações, o México só retomou a democracia em 2000, com a eleição de Fox e a saída do PRI do poder central. Já o Brasil retornou à democracia um pouco antes, a partir de 1985, com a saída dos militares do poder e o encaminhamento da política nacional e das instituições estatais ao controle de governos civis, além da recondução do país ao legítimo estado de direito, com o restabelecimento das garantias civis, políticas e sociais.

Para Weffort (1990), a América Latina da década de 1980, afundada em crises financeiras e de gestão, foi salva pela 
Artigo original

Hegemonia - Revista Eletrônica de Relações Internacionais do Centro Universitário Unieuro

ISSN: $1809-1261$

UNIEURO, Brasília, número 10, 2012, pp. 4-19.

redemocratização, de forma que na década seguinte a crise perdurava, mas os governos autoritários haviam desaparecido quase que completamente, e onde ainda permanecia apresentava uma fragilidade que não the deixaria seguir a passos firmes. Esta foi a década mais emblemática da região: ano a ano, em efeito cascata, os valores da democracia climatizaram a atmosfera latinoamericana, assim como de outras partes do mundo, sob influência das graves crises econômicas e políticas internacionais, incluindo a socialista que resultou, ao final desta década e início da seguinte, na derrubada do Muro de Berlin e na dissolução da União Soviética, respectivamente.

Porém, a sociedade mexicana, que não viveu o choque de governos militares neste período recente, não enxergou elementos suficientes para mobilizar os movimentos sociais em torno de mudanças estruturais, como ocorrido em outras sociedades da região, e por isso alargou sua semidemocracia até 1999, sendo um dos últimos países do Continente a se reencontrar com a democracia. Um grito destacado neste país partiu de Chiapas, em 1994, quando os zapatistas se externaram ao mundo contra o Nafta (Holloway, 2002).

\section{A formação do Nafta e do Mercosul}

Na América do Norte, as incertezas permearam as relações entre governantes desde o fim da Guerra Fria e o surgimento de novos mercados de produção e consumo sem o controle dos Estados Unidos, 
Artigo original

Hegemonia - Revista Eletrônica de Relações Internacionais do Centro Universitário Unieuro

ISSN: $1809-1261$

UNIEURO, Brasília, número 10, 2012, pp. 4-19.

que refizeram suas metas políticas e econômicas para a região, de onde surgiu o projeto do Nafta. O México foi convidado a compor o grupo em 1992, em acordo firmado entre os presidentes George Bush e Salinas de Gotari.

Em seguida, enquanto os mexicanos enxergavam neste acordo uma ascensão econômica no cenário internacional e a recuperação do estagnado mercado de trabalho local, as negociações enfrentaram desgastes nos Estados Unidos com o governo de Bill Clinton, incluindo contestações dentro do próprio Partido Democrata. Nesta discussão, os sindicalistas americanos temiam o desemprego com a adesão do México ao livre-comércio, cientes de que muitas empresas abandonariam os Estados Unidos em direção ao país vizinho, onde os salários são mais baixos. Os ambientalistas, por sua vez, também temiam este acordo, afirmando que as fábricas se instalariam no norte do México, onde a falta de infraestrutura e de legislações rígidas de proteção ambiental permitiriam a poluição local e esta, inevitavelmente, atingiria os Estados Unidos.

Através do empenho pessoal do presidente Clinton na viabilização do projeto, a Câmara e o Senado aprovaram a entrada dos Estados Unidos no Nafta. No Canadá, a aprovação pelo Parlamento ocorreu mediante persuasão do Partido Conservador Progressista, que conduzia o governo na época. No México, a aprovação pelo Congresso deu-se mediante pedido do presidente Salinas e concordância do PRI, que se mantinha com maioria absoluta 
Artigo original

Hegemonia - Revista Eletrônica de Relações Internacionais do Centro Universitário Unieuro

ISSN: $1809-1261$

UNIEURO, Brasília, número 10, 2012, pp. 4-19.

dos parlamentares, inclusive com a unanimidade das cadeiras no Senado.

Na América do Sul, os governos civis não tinham outro rumo que não fosse a consolidação do processo democrático, fazendo envolver-se o cidadão, atentando para suas necessidades com a promoção de políticas sociais. Com isso, não havia outra alternativa às novas democracias sulamericanas a não ser consolidar o curso já iniciado. Para isto os Estados dependiam de sua capacidade de retomar o desenvolvimento econômico, e este desenvolvimento dependia de sua capacidade de integração. Assim, reforçaram-se as ações conjuntas entre Brasil, Argentina, Uruguai e Paraguai para alavancar o mercado regional.

O Mercosul foi criado no início da última década do século passado com a assinatura do Tratado de Assunção. Apesar de instituído em 1991, os esforços para se chegar a este acordo são bastante anteriores, datando da década de 1980, que coincide com o período de alterações profundas nas políticas dos países latinoamericanos. Estas consistiam, não apenas na abertura política, mas também na abertura econômica. Neste momento, os governos da Argentina e do Brasil assinaram diversos acordos bilaterais. Mas também foram estes dois países, as principais potências econômicas da região, que por vezes colocaram em descaminho o plano do mercado comum. 
Artigo original

Hegemonia - Revista Eletrônica de Relações Internacionais do Centro Universitário Unieuro

ISSN: $1809-1261$

UNIEURO, Brasília, número 10, 2012, pp. 4-19.

A Argentina impôs barreiras aos setores de linha branca e automobilístico do Brasil, concebendo que a entrada desses produtos destruiria a indústria argentina. Também na agricultura surgiram impasses, quando os argentinos criticaram o subsídio oferecido pelo governo brasileiro aos produtores de açúcar, o que fazia com que ente produto entrasse no país vizinho com um preço reduzido, prejudicando o produtor local. A Argentina ainda estabeleceu barreiras aos calçados e aos tecidos brasileiros, o que levou o Brasil a recorrer à Organização Mundial do Comércio em 1999. Por outro lado, neste mesmo ano o Mercosul teve sua estabilidade ameaçada através da ação brasileira de desvalorização do Real, externando o frágil arcabouço institucional deste mercado comum, colocado em risco de desarticulação pela atuação unilateral do seu parceiro hegemônico.

\section{Observando os atores e os cenários}

Após a fixação de novas indústrias no México, em decorrência da consolidação do Nafta, novas oportunidades de trabalho foram levadas ao norte do país, com a significativa redução do desemprego e o incentivo à qualificação profissional, além do desenvolvimento no comércio local e dos investimentos em infraestrutura para atender às novas e crescentes demandas. Entretanto, a população das cidades fronteiriças foi bastante ampliada e uma elevada parcela de trabalhadores informais e do campo, inclusive do sul do país, 
Artigo original

Hegemonia - Revista Eletrônica de Relações Internacionais do Centro Universitário Unieuro

ISSN: $1809-1261$

UNIEURO, Brasília, número 10, 2012, pp. 4-19.

dependente basicamente da agricultura, ingressou na busca por um emprego no setor industrial.

Com esta configuração, o percentual da força de trabalho desempregada no país foi se elevando gradativamente e em uma década mais que dobrou. A taxa de desemprego no México foi de 2,5\% em 2000 e alcançou 5,5\% em 2009. Ainda assim, estes percentuais se mantêm inferiores aos registrados na mesma década no Brasil, onde esta taxa passou de 7,1\% em 2000 para $8,1 \%$ em 2009. Em 2010, mesmo com a recuperação econômica nos dois países, o percentual da população desempregada se manteve quase que o mesmo no México, 5,6\%, e caiu levemente no Brasil, chegando a $7 \%$.

Gráfico 1: Taxa de crescimento da produção industrial

Fonte: Indexmundi

Inicialmente, a produção industrial mexicana entrou em ascendência e o mercado de trabalho foi gradualmente aquecido com a instalação de parques industriais em seu território, apesar das novas indústrias utilizarem substancialmente novas tecnologias que reduziram a necessidade de mão de obra de baixa qualificação e criaram demandas por profissionais mais qualificados. Estes vieram, em grande parte, dos Estados Unidos. Na sequência, a geração de 


\section{Artigo original}

Hegemonia - Revista Eletrônica de Relações Internacionais do Centro Universitário Unieuro

ISSN: $1809-1261$

UNIEURO, Brasília, número 10, 2012, pp. 4-19.

empregos no México ficou atrelada à oscilação do consumo nos Estados Unidos. Com isso, as crises estadunidenses de 2001 e 2009 foram mais sintomáticas no México do que no Brasil, como visto nos Gráficos 1 e 2.

Gráfico 2: Taxa de Crescimento Real do PIB

Fonte: Indexmundi

Enquanto a produção brasileira seguiu um vetor mais uniforme, visto através do crescimento do PIB - Produto Interno Bruto, a produção mexicana foi mais instável, acompanhando o dinamismo da economia estadunidense. Este dinamismo, mais sensível às crises internacionais, se expande ao Nafta, com efeitos menores no Canadá e mais danosos no México, tendo em vista a capacidade interna de consumo do primeiro. No México, este efeito sequenciado reduz a autonomia do Estado diante do mercado e vincula, diretamente, a estabilidade econômica nacional a outro mercado e outro Estado, comprometendo assim a soberania nacional.

O crescimento dos investimentos externos no Brasil, como mostra a Tabela 1, demonstra, além da confiança do mercado internacional na regularidade política do país, a capacidade do mercado nacional de se expandir e atrair outros investimentos, bem 


\section{Artigo original}

Hegemonia - Revista Eletrônica de Relações Internacionais do Centro Universitário Unieuro

ISSN: $1809-1261$

UNIEURO, Brasília, número 10, 2012, pp. 4-19.

como o empenho do governo nacional na condução das finanças do Estado, na política de juros e no controle da inflação.

Tabela 1: Investimento Direto Estrangeiro* 
Artigo original

Hegemonia - Revista Eletrônica de Relações Internacionais do Centro Universitário Unieuro

ISSN: $1809-1261$

UNIEURO, Brasília, número 10, 2012, pp. 4-19. 


\section{Artigo original}

Hegemonia - Revista Eletrônica de Relações Internacionais do Centro Universitário Unieuro

ISSN: $1809-1261$

UNIEURO, Brasília, número 10, 2012, pp. 4-19.

Este posicionamento do governo brasileiro seguiu uma tendência regional, que teve início na última década do século $X X$, logo após a onda de redemocratização, mas que ganhou força na primeira década do século XXI, quando a maior parte da América Latina estava governada por grupos de esquerda (Sader, 2006) que priorizaram a aproximação dos mercados locais em detrimento do mercado dos Estados Unidos. Esta observação, que configura o desgaste dos partidos de direita na região, representa o fortalecimento de grupos que priorizaram os processos regionais de integração. Neste momento ocorreu a recuperação das economias nacionais, com o cenário econômico internacional favorável à importação dos produtos regionais. Desta forma, mesmo com a redução no ritmo de crescimento da economia dos Estados Unidos, as exportações permaneceram estáveis, graças ao crescimento na demanda de mercados ascendentes, como o Brasil e a China. 


\section{Artigo original}

Hegemonia - Revista Eletrônica de Relações Internacionais do Centro Universitário Unieuro

ISSN: $1809-1261$

UNIEURO, Brasília, número 10, 2012, pp. 4-19.

Tabela 2: Exportações em 2008 (\% do total)

\begin{tabular}{|c|c|c|}
\hline & & $\begin{array}{l}\mathrm{C} \\
\mathrm{h} \\
\mathrm{i} \\
\mathrm{n} \\
\mathrm{a}\end{array}$ \\
\hline Argentina & 7,9 & $\begin{array}{l}9 \\
1 \\
1\end{array}$ \\
\hline Brasil & 14,0 & $\begin{array}{l}8 \\
1 \\
3\end{array}$ \\
\hline Paraguai & 1,6 & $\begin{array}{l}2 \\
1 \\
1\end{array}$ \\
\hline Uruguai & 3,5 & $\begin{array}{l}8 \\
6 \\
6\end{array}$ \\
\hline Canadá & 78,1 & $\begin{array}{l}2 \\
4 \\
4\end{array}$ \\
\hline EUA & $\cdots$ & $\begin{array}{l}5 \\
\prime \\
6\end{array}$ \\
\hline México & 73,6 & 1 \\
\hline
\end{tabular}


Artigo original

Hegemonia - Revista Eletrônica de Relações Internacionais do Centro Universitário Unieuro

ISSN: $1809-1261$

UNIEURO, Brasília, número 10, 2012, pp. 4-19.

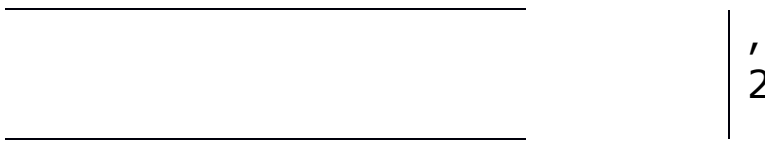

Fonte: Itamaraty

Com o comércio externo mexicano dirigido quase que exclusivamente aos Estados Unidos, como mostra a Tabela 2, em qualquer movimento de retração da economia estadunidense há efeitos que prejudicam direta e imediatamente o seu parceiro (Biz, 2004). Enquanto no Nafta as relações são mais assimétricas, havendo uma dependência maior dos países membros em relação aos Estados Unidos, no Mercosul, apesar da potencialidade brasileira, exercendo o papel de global player, as relações são mais equilibradas e os atores atuam de forma mais independente. Esta é outra marca da liderança brasileira na região, a da não-intervenção. De acordo com Amorim (2005), o país se pauta pela não-intervenção em assuntos internos de outros Estados, porém essa não-intervenção não significa falta de interesse ou indiferença, mas o respeito à soberania de cada nação e a confiança nas soluções negociadas.

Por outro lado, entre os países membros deste mercado, a dependência diante dos Estados Unidos foi amplamente reduzida, enquanto as relações entre os mercados envolvidos foram sobremaneira ampliadas, significando a redução dos efeitos externos das crises internacionais. Para os países do Mercosul, o crescimento na produção regional e a elevação das importações chinesas reduziram a dependência dos Estados Unidos. E tanto no Mercosul quanto na América Latina, a política externa brasileira se apresenta 
Artigo original

Hegemonia - Revista Eletrônica de Relações Internacionais do Centro Universitário Unieuro

ISSN: $1809-1261$

UNIEURO, Brasília, número 10, 2012, pp. 4-19.

com interesses na maior articulação regional em virtude do seu projeto de liderança, visível também em seu posicionamento como principal mantenedor dos custos da integração regional.

\section{Considerações finais}

Historicamente, o México sempre esteve apartado na América do Norte, e ao mesmo tempo, por sua posição geográfica, afastado da América Latina. O Nafta trouxe-Ihe a possibilidade de corrigir a primeira questão, mas a integração, mesmo com a América Central, permanece insipiente. O posicionamento da diplomacia mexicana continua bastante ligado aos acordos bilaterais com os Estados Unidos, basicamente, e em menor escala com outros países.

Diferente do México, a diplomacia brasileira apostou na construção de uma liderança regional política e econômica, com autonomia perante os Estados Unidos e articulada com o fortalecimento do país no cenário internacional enquanto global player. Esta diplomacia autonomista reforçou as instâncias multilaterais e agregou os países da região, a partir da centralidade brasileira. Como identifica Saraiva (2010), o posicionamento do Itamaraty orientou-se pela integração regional, com a crença na existência de uma identidade comum à região, propondo o aprofundamento desta relação em termos políticos, econômicos, sociais e culturais. 


\section{Artigo original}

Hegemonia - Revista Eletrônica de Relações Internacionais do Centro Universitário Unieuro

ISSN: $1809-1261$

UNIEURO, Brasília, número 10, 2012, pp. 4-19.

Para o Brasil, a abrangência dos esforços para toda a América Latina significaria o seu fortalecimento no cenário internacional como global player, mas geraria o desgaste enquanto paymaster. Isto tem implicado um maior envolvimento do governo brasileiro com as demandas sulamericanas, mas não o afastamento das questões latinoamericanas. A construção da liderança brasileira na América do Sul está marcada pela posição que o país tem assumido na cooperação com países de menos recursos, cabendo-Ihe os principais investimentos em infraestrutura, transferência de tecnologia e cooperação científica, o que o mantém em posição de centralidade.

\section{Bibliografia}

AMORIM, Celso. A política externa do governo Lula: os dois primeiros anos. Análise de conjuntura, n. 4, Rio de Janeiro, 2005.

BIZ, Osvaldo. O México no Nafta: negociação de igualdade entre desiguais? ADPPUCRS, n. 5, Porto Alegre, 2001.

DAHL, Robert. Polyarchy: participation and opposition. New Haven, Yale University Press, 1971.

HOLLOWAY, John. O zapatismo e as ciências sociais na América Latina. Novos Rumos, n. 36, São Paulo, 2002. 


\section{Artigo original}

Hegemonia - Revista Eletrônica de Relações Internacionais do Centro Universitário Unieuro

ISSN: $1809-1261$

UNIEURO, Brasília, número 10, 2012, pp. 4-19.

MAINWARING, Scott; BRINKS, Daniel; PÉREZ-LIÑAN, Aníbal. Classificando Regimes Políticos na América Latina, 1945-1999. Dados, n. 4, Rio de Janeiro, 2001.

SADER, Emir. O longo ciclo eleitoral latinoamericano. OSAL, n. 21, Buenos Aires, 2006.

SARAIVA, Miriam Gomes. Política externa brasileira para os países sulamericanos durante o governo Lula: entre a América do Sul e o Mercosul. VII Encontro ABCP, Recife, 2010.

WEFFORT, Francisco. A América Errada: notas sobre a democracia e a modernidade na América Latina em crise. Lua Nova, n. 21, São Paulo, 1990. 